Article

\title{
Investigation of MXenes Oxidation Process during SPS Method Annealing
}

\author{
Jaroslaw Wozniak ${ }^{1, *}$, Mateusz Petrus ${ }^{1}{ }^{\circledR}$, Tomasz Cygan ${ }^{1} \oplus$, Artur Lachowski ${ }^{1}$, Marek Kostecki ${ }^{1}{ }^{\circledR}$, \\ Agnieszka Jastrzębska ${ }^{1}{ }^{\mathbb{D}}$, Anita Wojciechowska ${ }^{1}$, Tomasz Wojciechowski ${ }^{2}$ and Andrzej Olszyna ${ }^{1}$ (D) \\ 1 Faculty of Material Science and Engineering, Warsaw University of Technology, ul. Wołoska 141, \\ 02-507 Warsaw, Poland; mateusz.petrus.dokt@pw.edu.pl (M.P.); tomasz.cygan.dokt@pw.edu.pl (T.C.); \\ artur@unipress.waw.pl (A.L.); marek.kostecki@pw.edu.pl (M.K.); agnieszka.jastrzebska@pw.edu.pl (A.J.); \\ anita.wojciechowska.dokt@pw.edu.pl (A.W.); andrzej.olszyna@pw.edu.pl (A.O.) \\ 2 Faculty of Chemistry, Warsaw University of Technology, Noakowskiego 3, 00-664 Warsaw, Poland; \\ t.wojciechowski@pw.edu.pl \\ * Correspondence: jaroslaw.wozniak@pw.edu.pl
}

Citation: Wozniak, J.; Petrus, M.; Cygan, T.; Lachowski, A.; Kostecki, M.; Jastrzębska, A.; Wojciechowska, A.; Wojciechowski, T.; Olszyna, A. Investigation of MXenes Oxidation Process during SPS Method Annealing. Materials 2021, 14, 6011. https://doi.org/10.3390/ma14206011

Academic Editor: Zoltán Erdélyi

Received: 9 September 2021

Accepted: 11 October 2021

Published: 12 October 2021

Publisher's Note: MDPI stays neutral with regard to jurisdictional claims in published maps and institutional affiliations.

Copyright: (c) 2021 by the authors. Licensee MDPI, Basel, Switzerland. This article is an open access article distributed under the terms and conditions of the Creative Commons Attribution (CC BY) license (https:// creativecommons.org/licenses/by/ $4.0 /)$.

\begin{abstract}
This paper discusses the effects of the environment and temperature of the $\mathrm{Ti}_{3} \mathrm{C}_{2}$ (MXene) oxidation process. The MXene powders were annealed at temperatures of 1000, 1200, 1400, 1600, and $1800{ }^{\circ} \mathrm{C}$ in argon and vacuum using a Spark Plasma Sintering (SPS) furnace. The purpose of the applied annealing method was to determine the influence of a high heating rate on the MXene degradation scheme. Additionally, to determine the thermal stability of MXene during the sintering of $\mathrm{SiC}$ matrix composites, $\mathrm{SiC}-\mathrm{C}-\mathrm{B}-\mathrm{Ti}_{3} \mathrm{C}_{2}$ powder mixtures were also annealed. The process parameters were as follows: Temperatures of 1400 and $1600{ }^{\circ} \mathrm{C}$, and pressure of $30 \mathrm{MPa}$ in a vacuum. Observations of the microstructure showed that, due to annealing of the $\mathrm{SiC}-\mathrm{C}-\mathrm{B}-\mathrm{Ti}_{3} \mathrm{C}_{2}$ powder mixtures, porous particles are formed consisting of $\mathrm{TiC}_{1} \mathrm{Ti}_{3} \mathrm{C}_{2} \mathrm{sym}$, and amorphous carbon. The formation of porous particles is a transitional stage in the formation of disordered carbon structures.
\end{abstract}

Keywords: microstructure; oxidation; MXenes; $\mathrm{Ti}_{3} \mathrm{C}_{2}$

\section{Introduction}

In the last decade, there has been a lot of interest in materials with a 2D structure. This is related to their unique properties and possible applications. Some of the most interesting materials with a 2D structure are the MXene phases. They were first described in 2011 [1]. They are obtained from the MAX phases, the name of which relates directly to their stoichiometry. $\mathrm{M}$ is a transition metal $(\mathrm{Ti}, \mathrm{V}, \mathrm{Cr}, \mathrm{Nb}$, etc.), $\mathrm{A}$ is a metal from groups 13 or $14(\mathrm{Al}, \mathrm{Si}$, etc.), and $\mathrm{X}$ is nitrogen or carbon, $\mathrm{n}=1.2$ or 3 [2-4]. Their structure includes $M_{n}+1 X_{n}$ layers with strong covalent bonds. These layers are connected by much weaker M-A bonds. A significant difference in the energy of these bonds made it possible to remove A atoms, which allowed one to obtain two-dimensional crystals with $M_{n}+1 X_{n}$ stoichiometry [5]. This MXene composition and graphene-like structure make them auspicious materials for supercapacitors [6], lithium-ion batteries [7-9], hydrogen storage [10], lead absorption [11], or catalysts [12].

Due to the extensive surface area of MXene, these materials are susceptible to environmental influences. Considering the significant influence of temperature on environmental factors, the thermal stability of MXene is a significant factor as it can affect the applicability of these materials. The thermal stability of MXene has been discussed in several publications. Lotfi et al. [13] simulated the oxidation of $\mathrm{Ti}_{3} \mathrm{C}_{2}$ MXene in various environments (dry air, wet air, hydrogen peroxide) at temperatures ranging from 1000 to $3000 \mathrm{~K}$. The research showed a significant influence of the environment on the rate of the oxidation process. In the first stage of oxidation, diffusion of $\mathrm{Ti}$ atoms from the middle layer to the MXene surface and the formation of the Ti-O bond were observed. This resulted in 
the formation of carbon structures which were further degraded at higher temperatures. Naguib et al. [14] obtained similar results. The oxidation process of MXene was carried out using rapid oxidation. The process was carried out at the temperature of $1150{ }^{\circ} \mathrm{C}$ for $30 \mathrm{~s}$. As a result, it was observed that anatase and disordered carbon structures are formed during oxidation. Thermogravimetric studies also confirm the MXene oxidation pattern. Li et al. [15] conducted tests of the thermal stability of MXene in air and argon at temperatures up to $1000{ }^{\circ} \mathrm{C}$. They observed a similar oxidation pattern regardless of the atmosphere used. However, although the thermal stability at higher temperatures was greater for argon annealed samples, the authors did not observe disordered carbon structure (DCS) formation. This was explained by a much longer heating time than in the case of the flash oxidation method. Despite the influence of the atmosphere used on the thermal stability of MXene, it is generally accepted that it is stable in the range of $800-1200{ }^{\circ} \mathrm{C}$.

A different approach to the thermal stability problem of MXene was presented by Petrus et al. [16]. They sintered SiC composites reinforced with MXene using the SPS (Spark Plasma Sintering) method. Although the composites were sintered at $1900{ }^{\circ} \mathrm{C}$ for $30 \mathrm{~min}$ in a vacuum, microstructure analysis revealed the presence of disordered carbon structures similar to those described by Naguib et al. [14]. The formation of carbon structures and their presence at such a high temperature are explained by the composition of the sintered $\mathrm{SiC}-\mathrm{C}-\mathrm{B}$ powder mixtures. The absence of oxide additives and sintering in a vacuum results in only a small amount of oxygen (adsorbed on the MXene surface) which favors the formation of carbon structures [17]. This can be confirmed by works describing the SPS sintering of composites on oxide matrices or with oxide additives, where MXene decomposes completely during the sintering process $[18,19]$. The presented works show that the thermal decomposition of MXene is relatively complicated and does not only depend on the atmosphere used or the heating method. The presence of other substances may affect the course and speed of the oxidation process.

This article aims to determine the effects of the environment and temperature on the oxidation of MXene.

\section{Materials and Methods}

\subsection{Materials}

$\mathrm{Ti}_{3} \mathrm{C}_{2}$-MXene powders were used to determine the effect of oxidation conditions on the rate and scheme of the oxidation process. The production scheme for $\mathrm{Ti}_{3} \mathrm{C}_{2}-\mathrm{MXene} \mathrm{has} \mathrm{been}$ described elsewhere [18]. In brief, $\mathrm{Ti}_{3} \mathrm{C}_{2}-\mathrm{MXene}$ preparation is carried out via acidic etching of the MAX $\mathrm{Ti}_{3} \mathrm{AlC}_{2}$ phase with concentrated (48\%) hydrofluoric (HF) acid under a fume hood protection. The mixture is then stirred at $1000 \mathrm{rpm}$ for $24 \mathrm{~h}$ until all available Al layers are removed. The resulting precipitate is separated from the acidic mixture and washed thoroughly with distilled water until the $\mathrm{pH}$ of the clay reaches about 7. Additionally, to study the degradation of MXene during the sintering process of composites on the $\mathrm{SiC}$ matrix, $\mathrm{SiC}-\mathrm{C}-\mathrm{B}-\mathrm{Ti}_{3} \mathrm{C}_{2}$ powder mixtures were annealed. The powder substrate used was comprised of: Commercial $\beta$-SiC (Alfa Aesar Haverhill, Massachusetts, USA, 99.8\% chemical purity, $0.42 \mu \mathrm{m}$ average particle size), amorphous boron powder (International Enzymes Limited Hampshire, UK, 96\% chemical purity, $0.39 \mu \mathrm{m}$ average particles size), and synthetic graphite powder (Sigma Aldrich St. Louis, MO, USA, 99\% chemical purity, average fake size below $20 \mu \mathrm{m}$ ).

\subsection{Annealing Process}

The MXene powder annealing process was carried out in a graphite die in an SPS furnace (HP D10, FCT System GmbH Effelder-Rauenstein, Germany) at temperatures of $1000,1200,1400,1600$, and $1800{ }^{\circ} \mathrm{C}$ in argon and in a vacuum. The powders were heated to the desired temperature at the rate of $100{ }^{\circ} \mathrm{C} / \mathrm{min}$ and then, after reaching the desired temperature, quickly cooled down to room temperature. In the case of annealing of $\mathrm{SiC}-\mathrm{C}-$ $\mathrm{B}-\mathrm{Ti}_{3} \mathrm{C}_{2}$ powder mixtures, the following parameters of the annealing process were used: 
Temperatures of 1400 and $1600{ }^{\circ} \mathrm{C}$ and pressure of $30 \mathrm{MPa}$ in a vacuum. After reaching the desired temperature, the powders were quickly cooled down to room temperature.

\subsection{Powders Characterization}

After annealing, $\mathrm{Ti}_{3} \mathrm{C}_{2}$-MXene was subjected to observation under a scanning electron microscope (SEM Hitachi 5500) (Hitachi, Tokyo, Japan). Additionally, optical absorption spectra were obtained using a UV-Vis spectrometer (Evolution 220, Thermo Scientific, Waltham, MA, USA) equipped with a Spectralon-covered ISA-220 integration sphere with a $60 \mathrm{~mm}$ diameter. Spectra were recorded in the range of $220-1100 \mathrm{~nm}$. The measurement parameters were: Scanning speed of $200 \mathrm{~nm} \mathrm{~min}^{-1}$, integration time of $0.30 \mathrm{~s}$, and resolution of $1.00 \mathrm{~nm}$. Total diffuse reflectance spectra measurements were made, on the basis of which, the band gap was calculated using the Kubelka-Munk function. The band gap is calculated by plotting the square product of the Kubelka-Munk function and the energy $\mathrm{F}$ (R) hv versus the energy hv. The band gap can be obtained by extending a straight line from the straight line segment touching the x-axis [20]. The Kubelka-Munk F (R) hv function is determined from Equation (1) [21].

$$
\mathrm{F}(\mathrm{R})=\mathrm{k} / \mathrm{s}
$$

where $\mathrm{k}$ - the molar absorption coefficient $\mathrm{k}=(1-\mathrm{R})^{2}$, $\mathrm{R}$-the reflectance data from the diffuse reflectance data, $\mathrm{S}$ - the scattering factor, $\mathrm{s}=2 \mathrm{Rh}$, hv-energy

As with pure MXene, the $\mathrm{SiC}-\mathrm{C}-\mathrm{B}-\mathrm{Ti}_{3} \mathrm{C}_{2}$ powder mixtures after annealing were also observed by scanning electron microscopy and analyzed using UV-Vis. Additionally, they were subjected to observations under a transmission electron microscope (TECNAI G2 F20 S-TWIN microscope operating at $200 \mathrm{kV}$ ) (FEI Technologies Inc., Oregon, United States).

Simulation of electron diffraction patterns and high-resolution TEM (Transmission electron microscopy) images were performed to find a possible crystal structure of the observed MXene phase. $\mathrm{A} \mathrm{Ti}_{3} \mathrm{C}_{2}$ unit cell from the Material Project database [22] (material ID: mp-1094034) was chosen as a reference unit cell for the MXene phase. For electron diffraction patterns and high-resolution TEM images simulations, PTCLab software [23] and QSTEM [24] code were used, respectively. The microscope settings in the simulation inputs corresponded to the TECNAI G2 F20 S-TWIN parameters and were fixed. Modification of the atom coordinates in the reference unit cell were made to obtain the best match between the experimental data and the simulations.

\section{Results}

Figure 1a-f shows the changes of the $\mathrm{Ti}_{3} \mathrm{C}_{2}$-MXene powder morphology after annealing in argon. With increasing temperature, the powders gradually oxidize on the surface, resulting in a slow disappearance of the layered structure of the powders.

At $1600{ }^{\circ} \mathrm{C}$, flake-shaped particles (Figure 1e) composed of smaller crystallites formed during the oxidation of MXene are visible. Powders annealed at the highest temperature (Figure 1f) lose their flake shape, which is related to the heating temperature close to the melting point of $\mathrm{TiO}_{2}$ [25]. A similar scheme of oxidation was observed for powders annealed in a vacuum (Figure 2a-e). Only a slightly lower degree of MXene oxidation was observed for powders annealed at the lowest temperatures of 1000 and $1200{ }^{\circ} \mathrm{C}$. At higher temperatures, an almost identical particle decomposition was observed, as in powders heated in argon. The analysis of the obtained results showed a typical degradation of MXene. Above $1200{ }^{\circ} \mathrm{C}$, the particles almost completely decomposed. The higher range of $\mathrm{Ti}_{3} \mathrm{C}_{2}$ MXene stability than reported in the literature [13] is probably related to the faster heating of the powder through the SPS method. Moreover, the occurrence of disordered carbon structures, the formation of which we described in our previous works, has not been observed. 

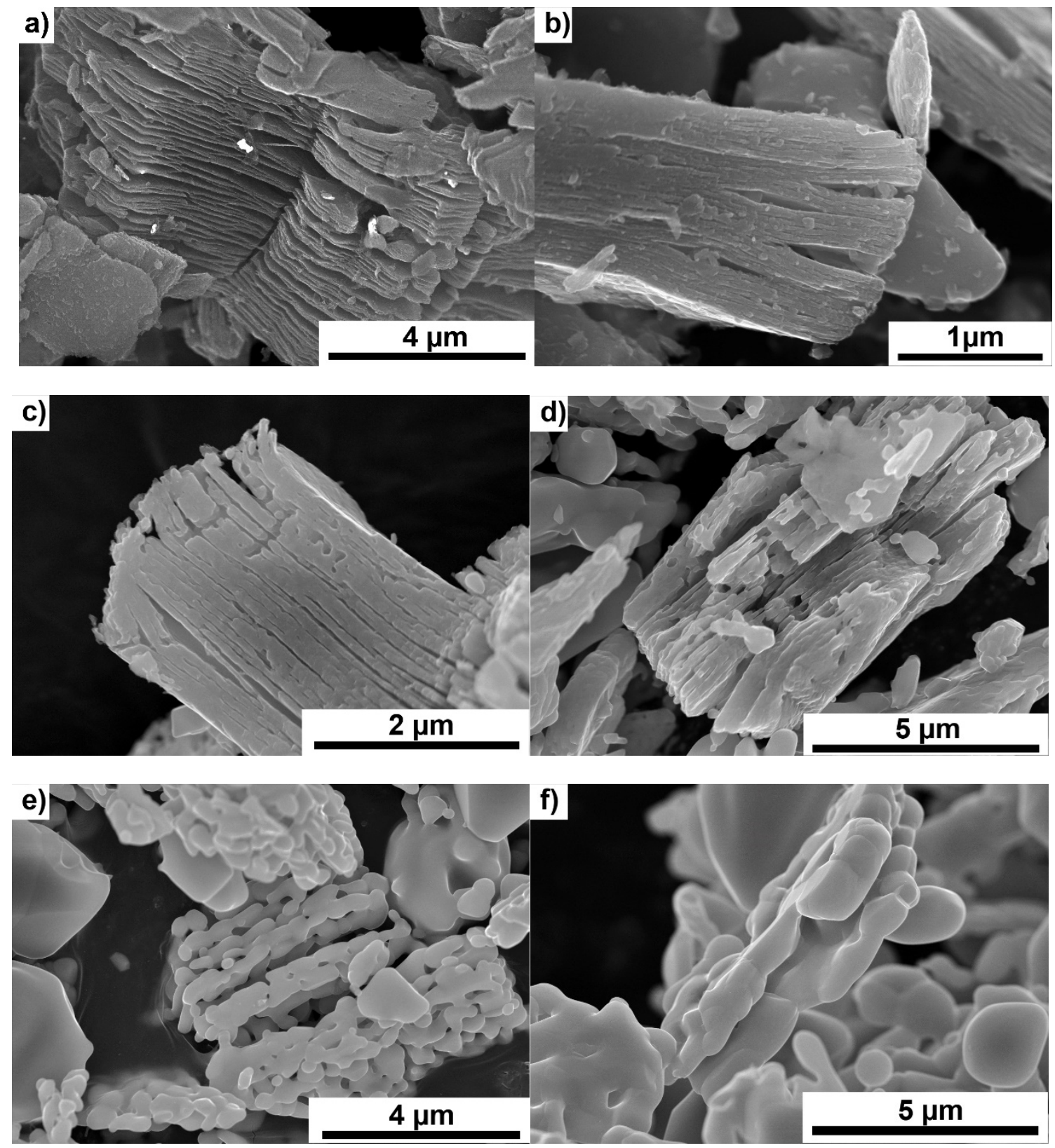

Figure 1. Morphology of $\mathrm{Ti}_{3} \mathrm{C}_{2}$ MXene powders; starting powder (a) powders annealed in argon at temperatures of (b) $1000{ }^{\circ} \mathrm{C}$, (c) $1200{ }^{\circ} \mathrm{C}$, (d) $1400{ }^{\circ} \mathrm{C}$, (e) $1600{ }^{\circ} \mathrm{C}$ and (f) $1800{ }^{\circ} \mathrm{C}$. 

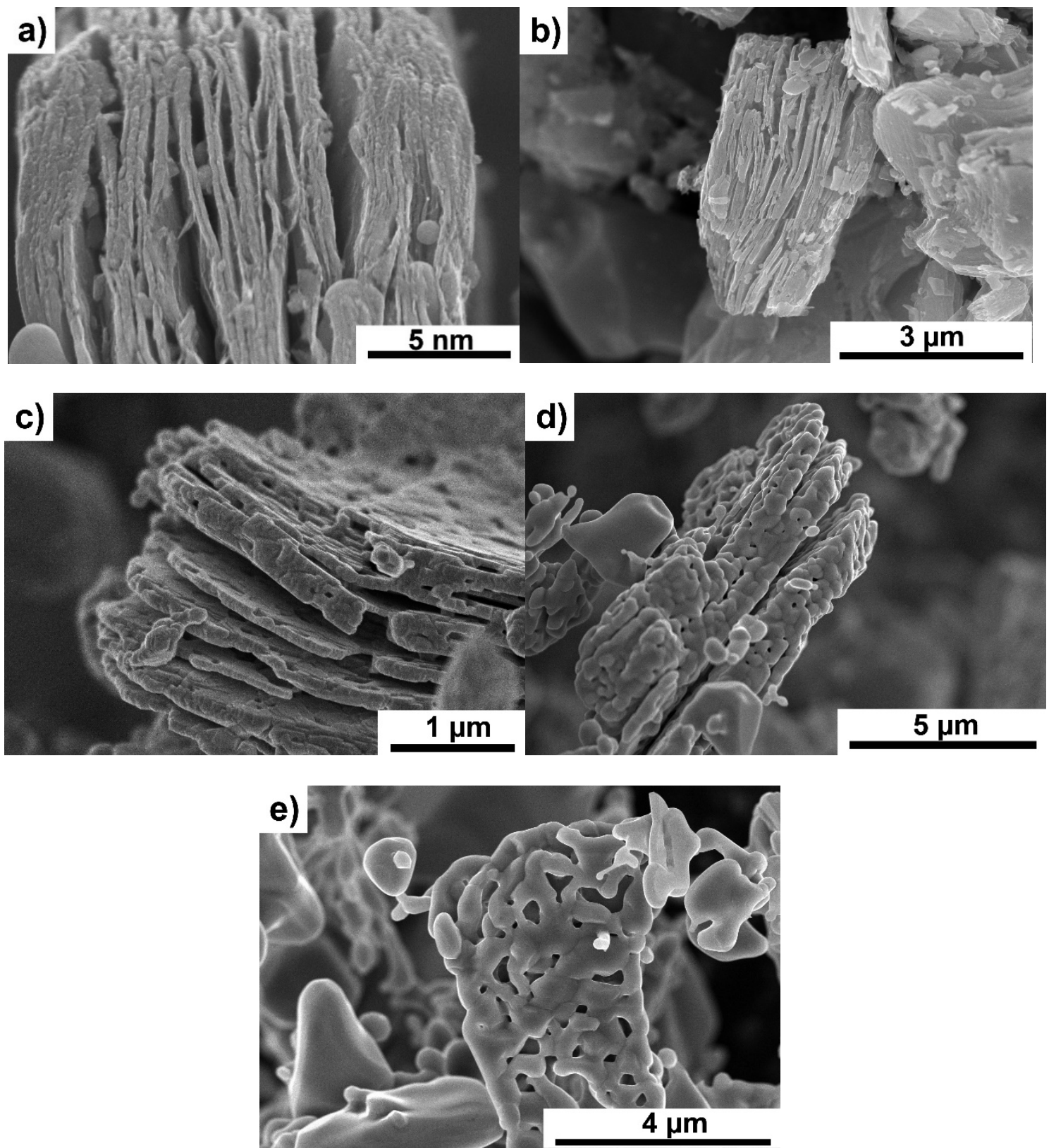

Figure 2. Morphology of $\mathrm{Ti}_{3} \mathrm{C}_{2} \mathrm{MXene}$ powders annealed in vacuum at temperatures of (a) $1000^{\circ} \mathrm{C},(\mathbf{b}) 1200^{\circ} \mathrm{C},(\mathbf{c}) 1400{ }^{\circ} \mathrm{C}$, (d) $1600{ }^{\circ} \mathrm{C}$ and (e) $1800^{\circ} \mathrm{C}$.

A comparison of the MXene degradation stages, depending on the annealing atmosphere, is presented in Figure 3. In both cases, the degradation process proceeds similarly. Above $1200{ }^{\circ} \mathrm{C}$, MXene is completely degraded, and its layered structure will be lost. A further increase in temperature causes the formation of particles composed of equiaxed crystallites. The only differences in degradation, depending on the atmosphere, can be seen at lower annealing temperatures. In the case of a vacuum, a slightly slower degradation can be observed compared to argon-annealed powders. The differences in the scheme of MXene degradation are related to the presence of adsorbed oxygen on the MXene surface, which is responsible for the oxidation processes during annealing. 


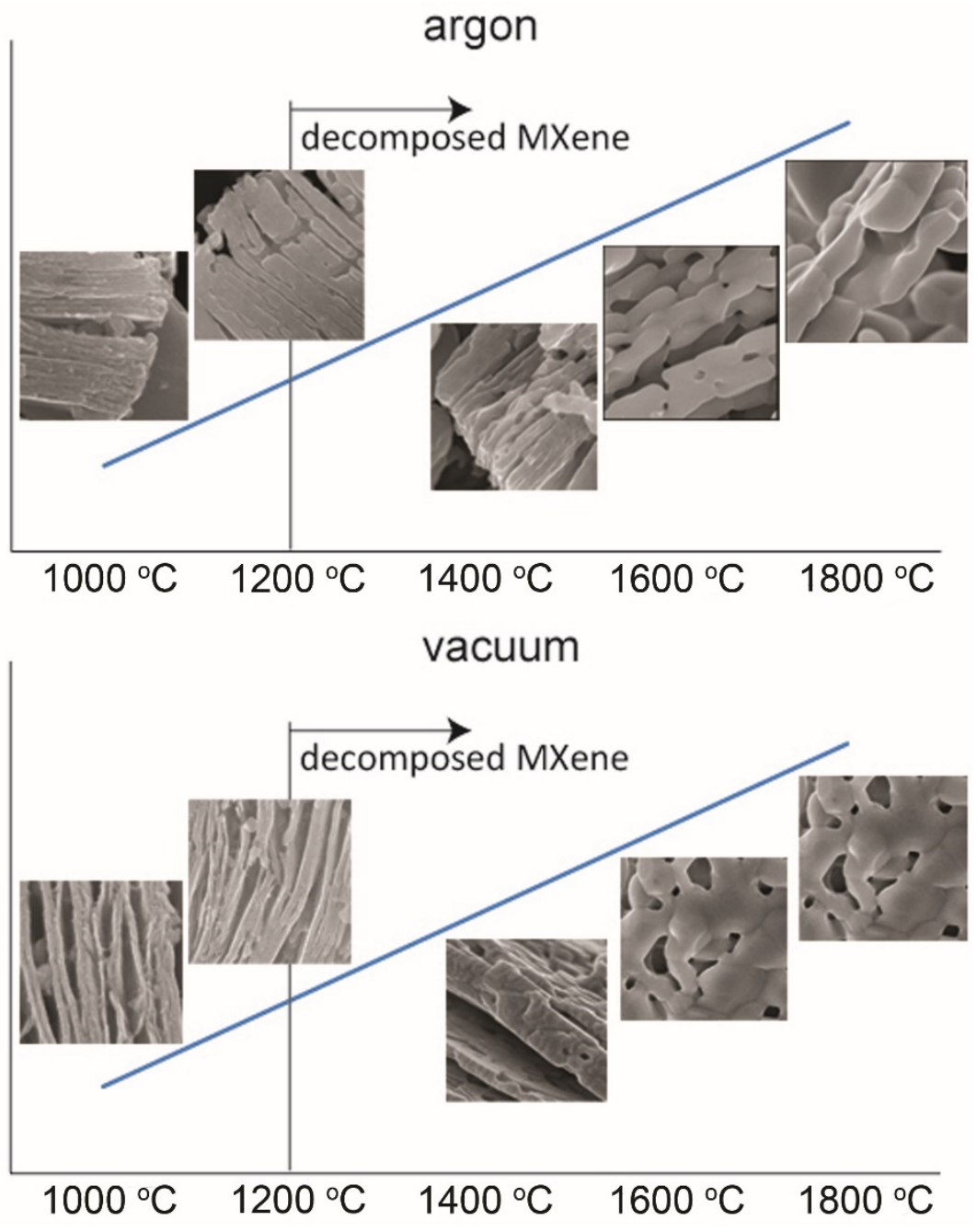

Figure 3. Diagram showing the decomposition steps of MXene annealed in argon and vacuum.

To identify the oxides present on the MXene surface, the bandgap value was determined. Exemplary test results are summarized in Figure $4 a, b$. By analyzing the obtained results, it can be concluded that all the tested materials contain the oxidized $\mathrm{Ti}_{3} \mathrm{C}_{2}$ phase. Its value for the bandgap is 1.1 for the MXene phase annealed under various conditions. In most of the tested materials, we also observe a peak for which the bandgap is from 3.2 to 3.3 related to the presence of $\mathrm{TiO}_{2}$ in the form of anatase on the surface of the tested materials [20]. The presence of anatase at such a high temperature $\left(1600^{\circ} \mathrm{C}\right)$ is quite surprising. According to the literature, the transformation of anatase to rutile takes place in the temperature range of $450-900^{\circ} \mathrm{C}$ [26]. However, the transformation process is dependent on many factors, including temperature, time, heating speed, particle size, morphology, surface area, and atmosphere [27]. Considering the annealing method that ensures rapid heating to a certain temperature, the process of transforming anatase to rutile could not have taken place due to the limited time of the process. 

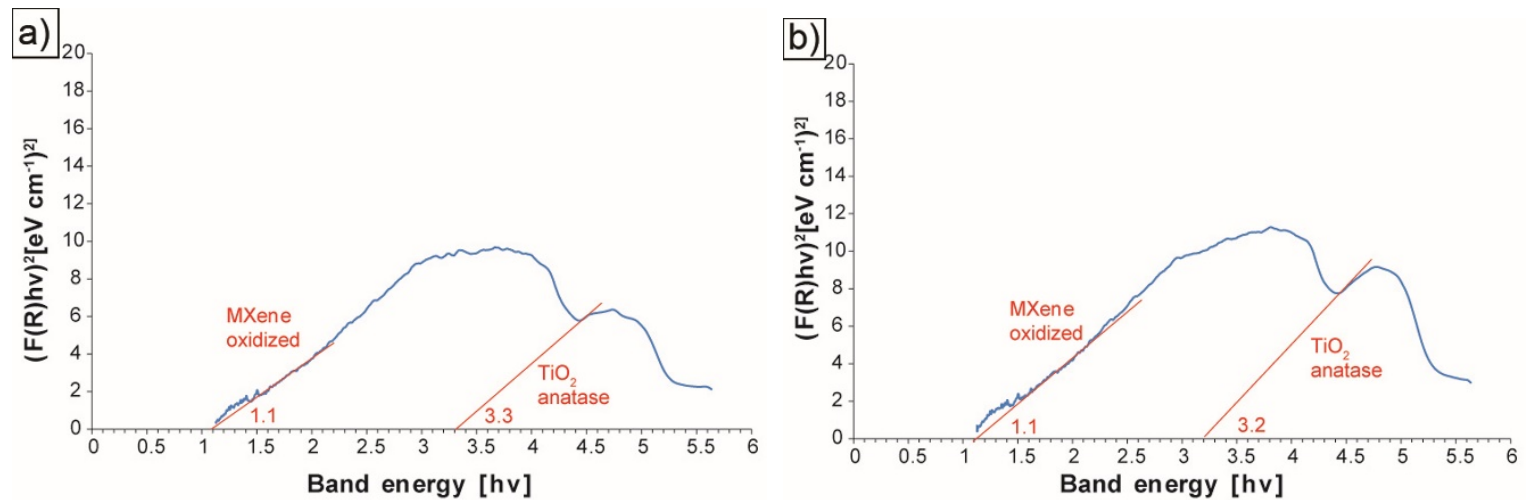

Figure 4. The plot of the Kubelka-Munk function in a function of band energy for $(\mathbf{a}) \mathrm{Ti}_{3} \mathrm{C}_{2} \mathrm{MXene}$ annealed at $1600{ }^{\circ} \mathrm{C}$ in argon, (b) $\mathrm{Ti}_{3} \mathrm{C}_{2}$ MXene annealed at $1600{ }^{\circ} \mathrm{C}$ in vacuum.

Because the observations of the MXene powders after the annealing process did not show the presence of disordered carbon structures, similar tests were carried out for the $\mathrm{SiC}-\mathrm{C}-\mathrm{B}-\mathrm{Ti}_{3} \mathrm{C}_{2}$ powder mixtures. This composition results from our previous work on the sintering of $\mathrm{SiC}$ composites reinforced with MXene, in which the presence of disordered carbon structures was observed. In these samples, due to the more complex composition (the presence of $\mathrm{SiC}, \mathrm{C}$, and B powders), the powders were observed in the form of loose powders and specially prepared samples enabling observation using the transmission electron microscope. In the case of lower annealing temperatures, the degradation of MXene occurred to a similar extent as in the case of annealing pure MXene (Figure 5a). A thicker oxide layer appears on the $\mathrm{Ti}_{3} \mathrm{C}_{2}$ surface. Much greater differences were observed for powders annealed at a temperature above $1600^{\circ} \mathrm{C}$. The presence of porous particles with a sponge-like structure was noted (Figure 5b). EDS (Energy-Dispersive Spectroscopy) analysis of these particles showed the presence of only carbon, which indicates a change in the degradation scheme of MXene in the presence of $\mathrm{SiC}-\mathrm{C}-\mathrm{B}$. The presence of porous particles, with a shape similar to MXene, proves the formation of the disordered carbon structures described in our previous papers [16]. However, the morphology of these particles differs from those we observed in the $\mathrm{SiC}$ matrix sinters [16,17].

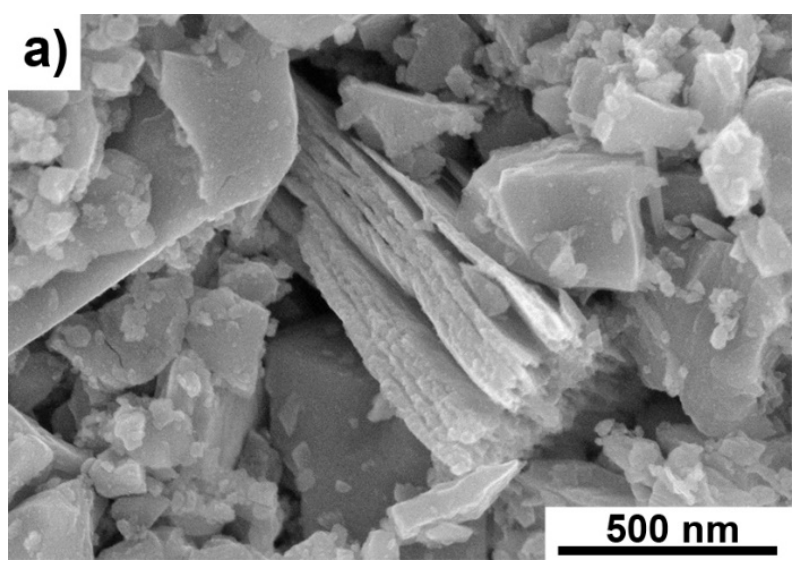

Figure 5. Cont. 


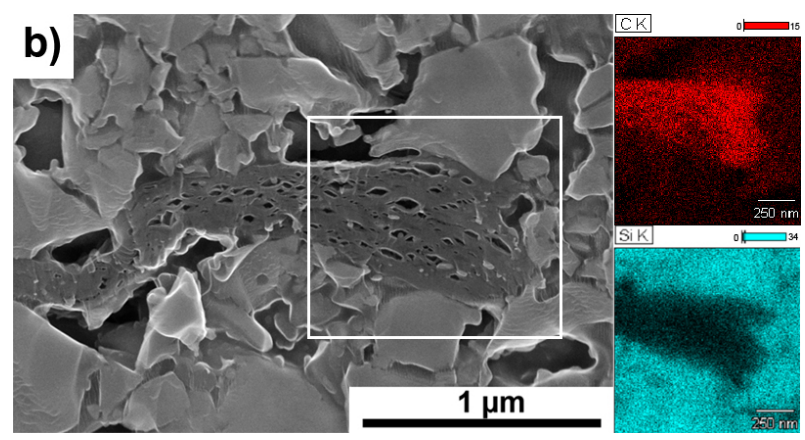

Figure 5. Morphology of $\mathrm{SiC}-\mathrm{C}-\mathrm{B}-\mathrm{Ti}_{3} \mathrm{C}_{2}$ powders annealed in vacuum (a) at $1400{ }^{\circ} \mathrm{C},(\mathbf{b})$ at $1600{ }^{\circ} \mathrm{C}$.

The disordered carbon structure particles did not show such porosity. This may indicate that the formation of porous particles is a transitional stage in the formation of disordered carbon structures. As in the case of annealed pure MXene, the bandgap value was determined for the identification of oxides on the MXene surface (Figure 6).

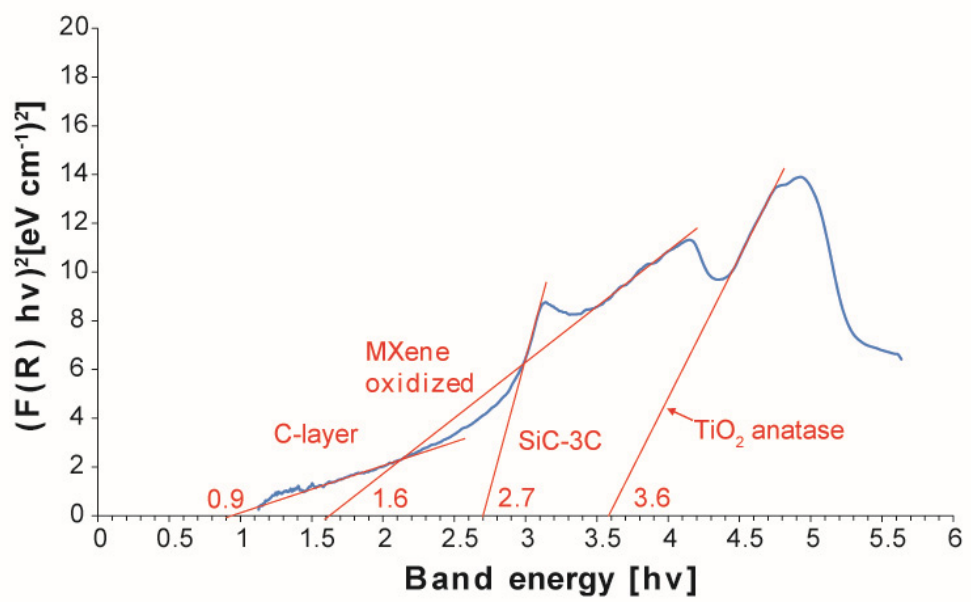

Figure 6. The plot of the Kubelka-Munk function in a function of band energy for $\mathrm{SiC}-\mathrm{C}-\mathrm{B}-\mathrm{Ti}_{3} \mathrm{C}_{2}$ MXene annealed at $1600^{\circ} \mathrm{C}$ in vacuum,.

Apart from oxidized MXene and anatase observed for pure powders, SiC-3C (bandgap $2.7 \mathrm{hv}$ ) and C-layer (bandgap $0.9 \mathrm{hv}$ ) were also identified. This confirms our SEM observations of the powder in which elongated particles with a high carbon content were identified. To fully characterize the observed particles, observations using a transmission electron microscope were carried out.

TEM analysis of SiC-C-B-MXene powders annealed at $1600{ }^{\circ} \mathrm{C}$ revealed the presence of two types of particles with an elongated shape. The first type of particles is presented in Figure 7a,b. TEM analysis showed that these particles are composed of carbon layers with amorphous regions on the surface of the particles. Our previous publication identified this type of particle as disordered carbon structures in the $\mathrm{SiC}$ matrix sinters [16]. However, it should be noted that the amount of DCS particles is much smaller compared to the second type of identified particles. The analysis of these particles is shown in Figure $8 \mathrm{a}, \mathrm{b}$. These are porous particles that have been observed with a scanning electron microscope. These particles consist of alternating elongated crystalline and amorphous regions. Analysis of the crystalline regions showed the presence of two phases. 

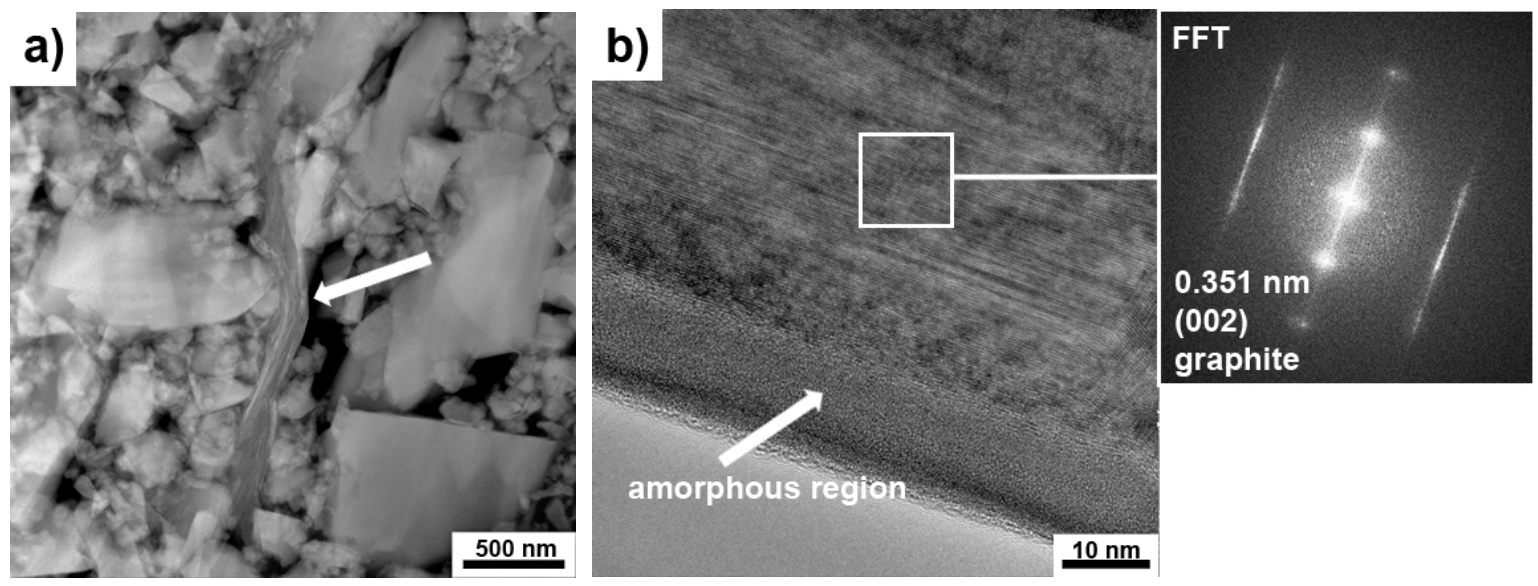

Figure 7. Transmission electron microscopy (TEM) analysis of $\mathrm{SiC}-\mathrm{C}-\mathrm{B}-\mathrm{Ti}_{3} \mathrm{C}_{2}$ powder after annealing at $1600{ }^{\circ} \mathrm{C}$ : (a) Disordered carbon structures, (b) high-resolution transmission electron microscopy (HRTEM) image and fast Fourier transform (FFT) pattern of DCS.
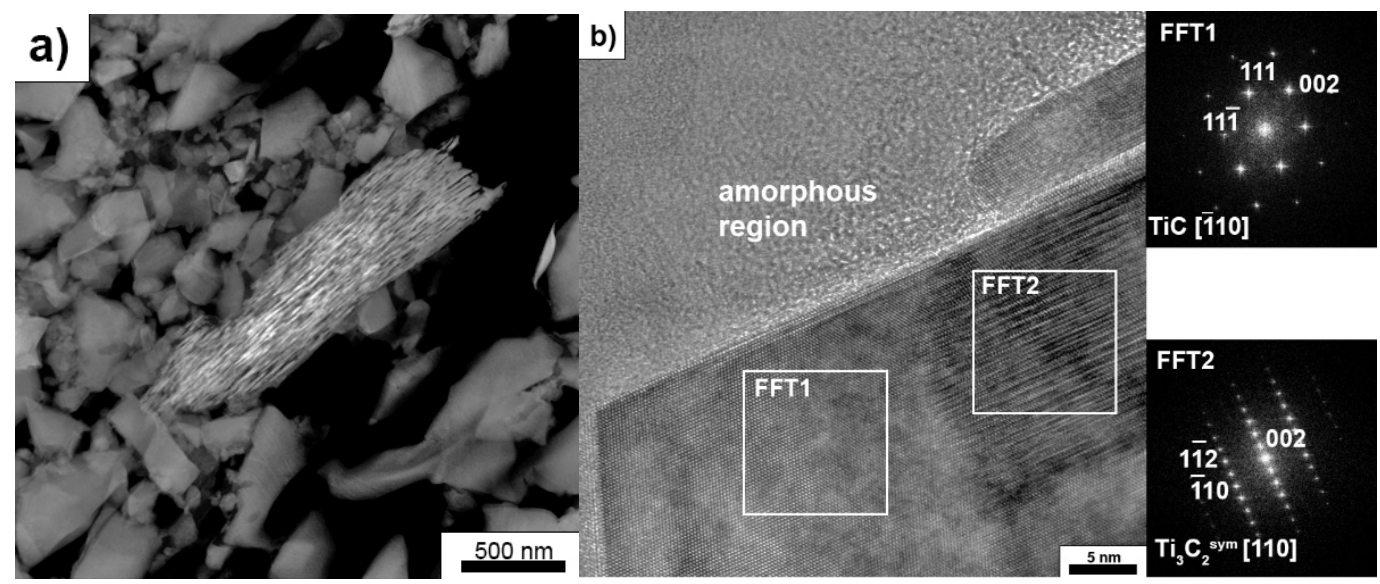

Figure 8. Transmission electron microscopy (TEM) analysis of $\mathrm{SiC}-\mathrm{C}-\mathrm{B}-\mathrm{Ti}_{3} \mathrm{C}_{2}$ powder after annealing at $1600{ }^{\circ} \mathrm{C}$ : (a) Porous layered structures, (b) high-resolution transmission electron microscopy (HRTEM) image and fast Fourier transform (FFT) pattern of porous layered structures.

The $\mathrm{TiC}$ was identified at the ends and in the interior areas of the elongated layers (Figure $8 \mathrm{~b}$ ) and a second phase, with a diffraction similar to that of $\mathrm{Ti}_{3} \mathrm{C}_{2}$. Moreover, analysis of the $\mathrm{TiC}$ fast Fourier transform (FFT) pattern showed the presence of a twin boundary. A similar formation of TiC twins has been described in the literature in the case of MAX phases [28]. A HRTEM image and FFT pattern of TiC twins are presented in Figure 9. The measured angles between (111) and (111) are $70^{\circ}$. 


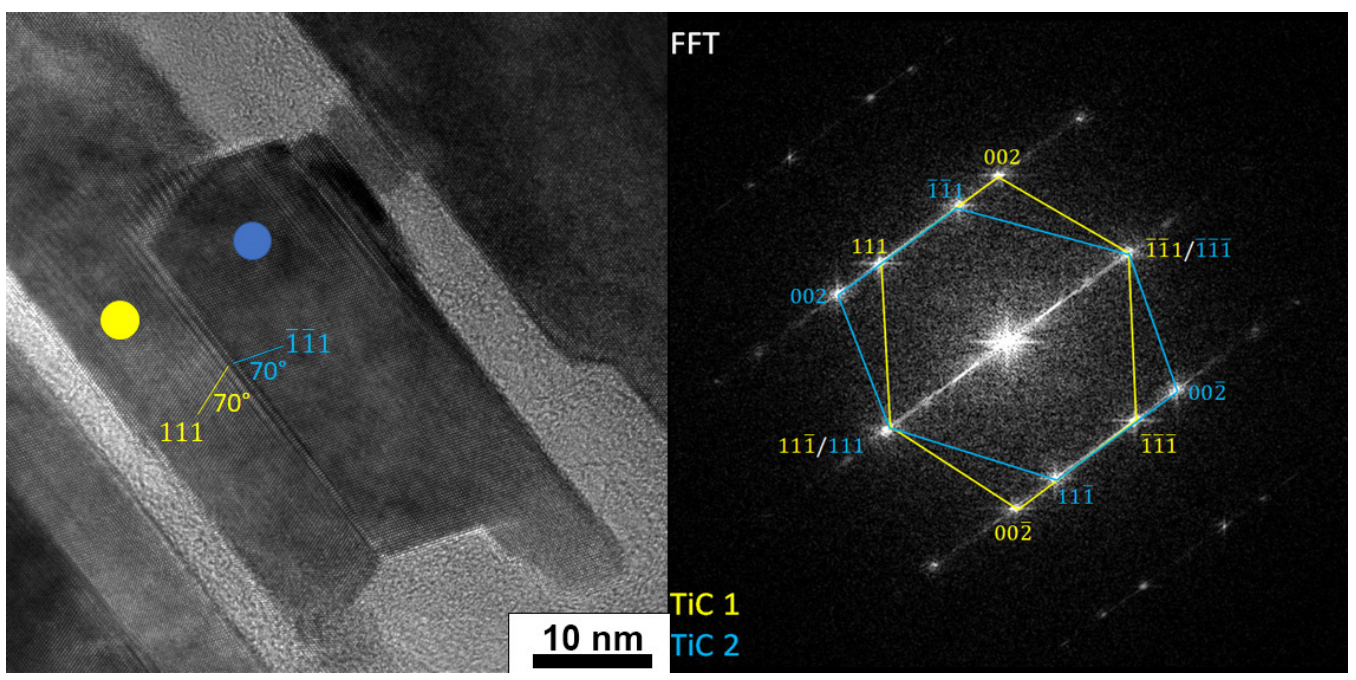

Figure 9. HRTEM image and fast Fourier transform (FFT) pattern of TiC twins.

However, there are some differences. As shown in the simulation for $\mathrm{Ti}_{3} \mathrm{C}_{2}$ (Figure 10a), there are (111) reflections in the zone axis, which were not identified on diffraction. However, it is enough to change the position of the Ti atoms (indicated by the arrows), as for $\mathrm{Ti}_{3} \mathrm{C}_{2}$ sym, and the diffraction pattern will be similar to the simulation. Additionally, there is a better match of the $\mathrm{Ti}_{3} \mathrm{C}_{2}$ sym structure to the HRTEM image than $\mathrm{Ti}_{3} \mathrm{C}_{2}$ (Figure 10b). In the case of $\mathrm{Ti}_{3} \mathrm{C}_{2}$, there is a change in the orientation of the atoms not observed in the experiment, where all atoms are arranged in one direction, exactly as for the $\mathrm{Ti}_{3} \mathrm{C}_{2}{ }^{\text {sym }}$ simulation. Based on the obtained research results, it is possible to propose a mechanism responsible for the formation of disordered carbon structures. According to the literature data, the starting $\mathrm{Ti}_{3} \mathrm{C}_{2}$ powder has twin boundaries [28]. Since these are high energy boundaries, $\mathrm{Ti}$ atoms are shifted during the annealing process, resulting in the formation of the $\mathrm{Ti}_{3} \mathrm{C}_{2}$ sym structure, as shown in Figure 10a. Further thermal activation leads to a redistribution of carbon atoms so that there are no Ti-Ti bonds, omitting $\mathrm{C}$. As a result of this process, $\mathrm{TiC}_{0.67}$ forms with twin boundaries and voids occur. Rapid temperature rises can occur in the voids leading to the removal of $\mathrm{Ti}$, which results in the formation of amorphous carbon regions between $\mathrm{TiC}_{0.67}$. This process is much more efficient at the particle edges of the MXene phases. Therefore, in the internal areas, the removal efficiency of titanium is lower, and there remain areas where $\mathrm{Ti}_{3} \mathrm{C}_{2}{ }^{\mathrm{sym}}$ occurs without twin boundaries. At a higher temperature, recrystallization and further removal of Ti occurs, resulting in the formation of defective carbon structures. Other authors observed a similar mechanism of decomposition as a result of the annealing of the MAX phases [28,29]. 
a) $\mathrm{Ti}_{3} \mathrm{C}_{2}$
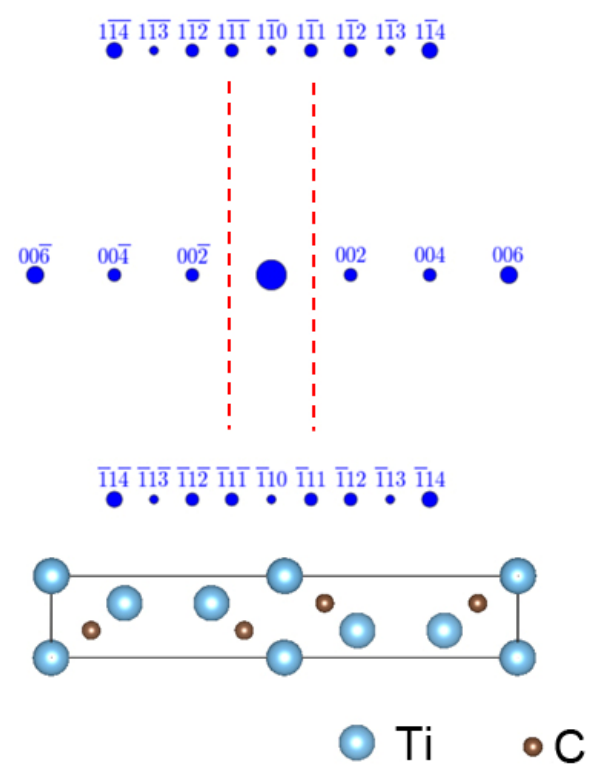

b)

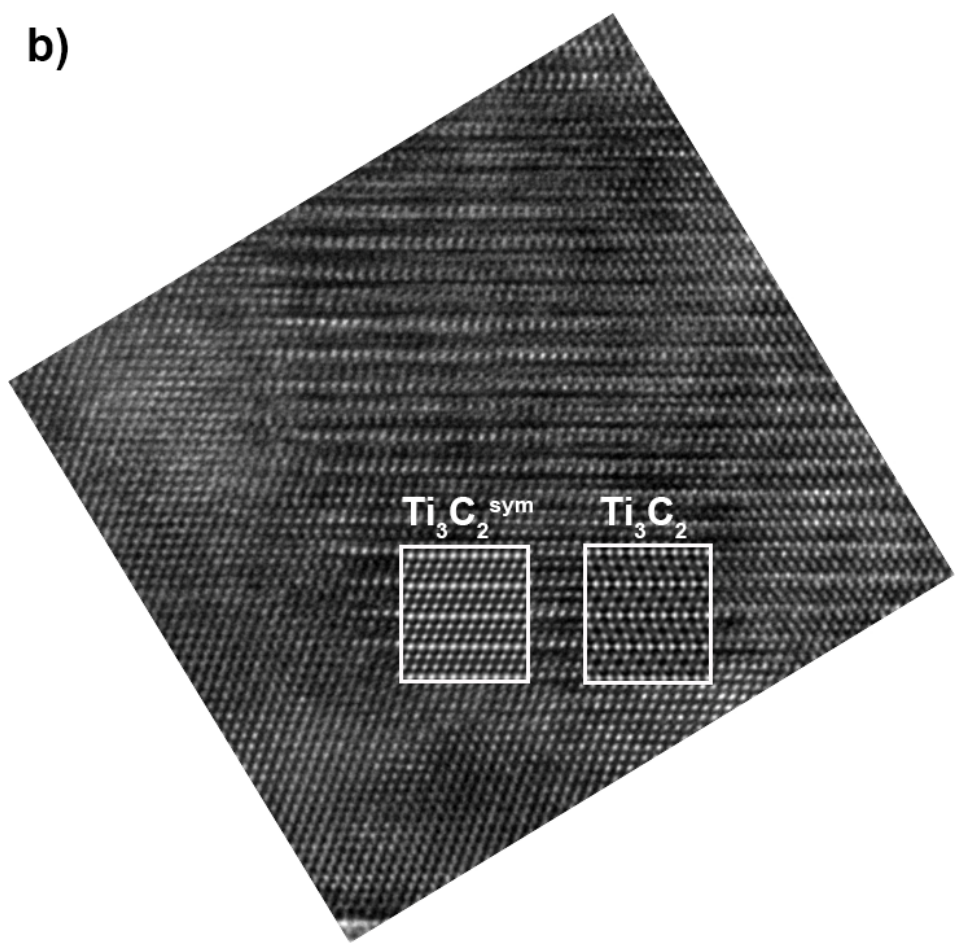

Figure 10. Simulation of $\mathrm{Ti}_{3} \mathrm{C}_{2}$ sym structure formation: (a) The way of performing simulation visualized using VESTA (ver. 3.5.7) (National Museum of Nature and Science, Tsukuba-shi, Japan) [30], (b) comparison of $\mathrm{Ti}_{3} \mathrm{C}_{2}$ and $\mathrm{Ti}_{3} \mathrm{C}_{2}{ }^{\text {sym }}$ structures to the structure obtained in the experiment.

\section{Conclusions}

In this work, research was carried out to determine the mechanism of MXene decomposition during annealing. The pure $\mathrm{Ti}_{3} \mathrm{C}_{2}$ powders annealed in both vacuum and argon showed a similar nature of degradation. As the temperature increased, the MXene particles became covered with an increasingly thicker layer of oxides. In the case of MXene annealed in the presence of $\mathrm{SiC}, \mathrm{B}$, and $\mathrm{C}$ powders, the particles decompose to form porous 
structures composed of $\mathrm{TiC}, \mathrm{Ti}_{3} \mathrm{C}_{2}$ sym, and amorphous carbon. The formation of porous structures is a transitional stage which consequently leads to the formation of defective carbon structures. The obtained test results are consistent with those obtained in our previous studies in which we postulated the influence of $\mathrm{SiC}, \mathrm{B}$, and $\mathrm{C}$ on the formation of disordered carbon structures.

Author Contributions: J.W., article concept, manuscript preparation, results analysis, MAX preparation; M.K., SEM observation; M.P. and T.C., powders annealing, MAX preparation; A.L., TEM ob-servation; A.J., A.W., T.W., MXene preparation, UV-Vis measurements; A.O., review and edition. All authors have read and agreed to the published version of the manuscript.

Funding: Studies were funded by Materials Technologies project granted by Warsaw University of Technology under the program Excellence Initiative: Research University (ID-UB).

Institutional Review Board Statement: Not applicable.

Informed Consent Statement: Not applicable.

Data Availability Statement: The data presented in this study are available on request from the corresponding author.

Conflicts of Interest: The authors declare no conflict of interest.

\section{References}

1. Naguib, M.; Kurtoglu, M.; Presser, V.; Lu, J.; Niu, J.; Heon, M.; Hultman, L.; Gogotsi, Y.; Barsoum, M.W. Two-dimensional nanocrystals produced by exfoliation of $\mathrm{Ti}_{3} \mathrm{AlC}_{2}$. Adv. Maters. 2011, 23, 4248-4253. [CrossRef] [PubMed]

2. Nowotny, V.H. Strukturchemie einiger Verbindungen der Übergangsmetalle mit den elementen C, Si, Ge, Sn. Prog. Solid State Chem. 1971, 5, 27-70. [CrossRef]

3. Jeitschko, W.; Nowotny, H.; Benesovsky, F. Die H-Phasen: $\mathrm{Ti}_{2} \mathrm{CdC}, \mathrm{Ti}_{2} \mathrm{GaC}, \mathrm{Ti}_{2} \mathrm{GaN}_{1} \mathrm{Ti}_{2} \mathrm{InN}_{2} \mathrm{Zr}_{2} \mathrm{InN}_{\mathrm{N}}$ und $\mathrm{Nb}_{2} \mathrm{GaC}$. Monatshefte Für Chemie 1964, 95, 178-179. [CrossRef]

4. Jeitschko, W.; Nowotny, H.; Benesovsky, F. Kohlenstoffhaltige ternäre Verbindungen (H-Phase). Monatshefte Für Chemie 1963, 94 , 672-676. [CrossRef]

5. Naguib, M.; Unocic, R.R.; Armstrong, B.L.; Nanda, J. Large-scale delamination of multi-layers transition metal carbides and carbonitrides "mXenes". Dalton Trans. 2015, 44, 9353-9358. [CrossRef]

6. Lukatskaya, M.R.; Mashtalir, O.; Ren, C.E.; Dall'Agnese, Y.; Rozier, P.; Taberna, P.L.; Naguib, M.; Simon, P.; Barsoum, M.W.; Gogotsi, Y. Cation intercalation and high volumetric capacitance of two-dimensional titanium carbide. Science 2013, 341, $1502-1505$. [CrossRef]

7. Tang, Q.; Zhou, Z.; Shen, P. Are MXenes promising anode materials for Li ion batteries? Computational studies on electronic properties and Li storage capability of Ti3C2 and Ti3C2X2 (X = F, OH) monolayer. J. Am. Chem. Soc. 2012, 134, 16909-16916. [CrossRef]

8. Sun, D.; Wang, M.; Li, Z.; Fan, G.; Fan, L.Z.; Zhou, A. Two-dimensional Ti3C2 as anode material for Li-ion batteries. Electrochem. Commun. 2014, 47, 80-83. [CrossRef]

9. Naguib, M.; Come, J.; Dyatkin, B.; Presser, V.; Taberna, P.L.; Simon, P.; Barsoum, M.W.; Gogotsi, Y. MXene: A promising transition metal carbide anode for lithium-ion batteries. Electrochem. Commun. 2012, 16, 61-64. [CrossRef]

10. Hu, Q.; Sun, D.; Wu, Q.; Wang, H.; Wang, L.; Liu, B.; Zhou, A.; He, J. MXene: A new family of promising hydrogen storage medium. J. Phys. Chem. A 2013, 117, 14253-14260. [CrossRef]

11. Peng, Q.; Guo, J.; Zhang, Q.; Xiang, J.; Liu, B.; Zhou, A.; Liu, R.; Tian, Y. Unique lead adsorption behavior of activated hydroxyl group in two-dimensional titanium carbide. J. Am. Chem. Soc. 2014, 136, 4113-4116. [CrossRef]

12. Gao, Y.; Wang, L.; Li, Z.; Zhou, A.; Hu, Q.; Cao, X. Preparation of MXene-Cu2O nanocomposite and effect on thermal decomposition of ammonium perchlorate. Solid State Sci. 2014, 35, 62-65. [CrossRef]

13. Lotfi, R.; Naguib, M.; Yilmaz, D.E.; Nanda, J.; Van Duin, A.C. A comparative study on the oxidation of two-dimensional Ti3C2 MXene structures in different environments. J. Mater. Chem. A 2018, 6, 12733-12743. [CrossRef]

14. Naguib, M.; Mashtalir, O.; Lukatskaya, M.R.; Dyatkin, B.; Zhang, C.; Presser, V.; Gogotsi, Y.; Barsoum, M.W. One-step synthesis of nanocrystalline transition metal oxides on thin sheets of disordered graphitic carbon by oxidation of MXenes. Chem. Commun. 2014, 50, 7420-7423. [CrossRef] [PubMed]

15. Li, Z.; Wang, L.; Sun, D.; Zhang, Y.; Liu, B.; Hu, Q.; Zhou, A. Synthesis and thermal stability of two-dimensional carbide MXene Ti3C2. Materi. Sci. Eng. B Solid-State Mater. Adv. Technol. 2015, 191, 33-40. [CrossRef]

16. Petrus, M.; Woźniak, J.; Cygan, T.; Lachowski, A.; Rozmysłowska-Wojciechowska, A.; Wojciechowski, T.; Ziemkowska, W.; Chlubny, L.; Jastrzębska, A.; Adamczyk-Cieślak, B.; et al. Silicon carbide nanocomposites reinforced with disordered graphitic carbon formed in situ through oxidation of $\mathrm{Ti}_{3} \mathrm{C}_{2}$ MXene during sintering. Arch. Civ. Mech. Eng. 2021, 21, 1-12. [CrossRef] 
17. Petrus, M.; Wo, J.; Cygan, T.; Lachowski, A.; Moszczy, D.; Adamczyk-Cie, B.; Rozmysłowska-Wojciechowska, A.; Wojciechowski, T.; Ziemkowska, W.; Jastrz, A.; et al. Influence of Ti3C2Tx MXene and Surface-Modified $\mathrm{Ti}_{3} \mathrm{C}_{2} \mathrm{Tx}$ MXene Addition on Microstructure and Mechanical Properties of Silicon Carbide Composites Sintered via Spark Plasma Sintering Method. Materials 2021, 14, 3558. [CrossRef] [PubMed]

18. Cygan, T.; Wozniak, J.; Petrus, M.; Lachowski, A.; Pawlak, W.; Adamczyk-Cieślak, B.; Jastrzębska, A.; RozmysłowskaWojciechowska, A.; Wojciechowski, T.; Ziemkowska, W.; et al. Microstructure and mechanical properties of alumina composites with addition of structurally modified $2 \mathrm{~d} \mathrm{Ti}_{3} \mathrm{C}_{2}$ (Mxene) phase. Materials 2021, 14, 829. [CrossRef]

19. Wozniak, J.; Petrus, M.; Cygan, T.; Lachowski, A.; Adamczyk-Cieślak, B.; Moszczyńska, D.; Jastrzębska, A.; Wojciechowski, T.; Ziemkowska, W.; Olszyna, A. Influence of MXene $\left(\mathrm{Ti}_{3} \mathrm{C}_{2}\right)$ Phase Addition on the Microstructure and Mechanical Properties of Silicon Nitride Ceramics. Materials 2020, 13, 5221. [CrossRef] [PubMed]

20. Abdullahi, S.S.; Güner, S.; Ibrahim, Y.; Musa, M.; Adamu, B.I.; Abdulhamid, M. Simple Method for the Determination of Band Gap of a Nanopowdered Sample Using Kubelka Munk Theory. J. Niger. Assoc. Math. Phys. 2016, 35, 241-246.

21. Zhang, J.; Xi, J.; Ji, Z. Mo + N Codoped TiO2 sheets with dominant $\{001\}$ facets for enhancing visible-light photocatalytic activity. J. Mater. Chem. 2012, 22, 17700-17708. [CrossRef]

22. Jain, A.; Ong, S.P.; Hautier, G.; Chen, W.; Richards, W.D.; Dacek, S.; Cholia, S.; Gunter, D.; Skinner, D.; Ceder, G.; et al. The Materials Project: A materials genome approach to accelerating materials innovation. APL Mater. 2013, 1, 011002. [CrossRef]

23. Gu, X.-F.; Furuhara, T.; Zhang, W.-Z. PTCLab: Free and open-source software for calculating phase transformation crystallography. J. Appl. Crystallogr. 2016, 49, 1099-1106. [CrossRef]

24. Koch, C. Determination of Core Structure Periodicity and Point Defect Density along Dislocations; Arizona State University: Tempe, Arizona, 2002.

25. Pierre, P.S. A Note on the Melting Point of Titanium Dioxide. J. Am. Ceram. Soc. 1952, 35, 188. [CrossRef]

26. Ghosh, T.B.; Dhabal, S.; Datta, A.K. On crystallite size dependence of phase stability of nanocrystalline TiO 2 . J. Appl. Phys. 2003, 94, 4577. [CrossRef]

27. Hanaor, D.; Sorrell, C.; Hanaor, D.A.H.; Sorrell, C.C. Review of the anatase to rutile phase transformation. J. Mater. Sci. 2011, 46, 855-874. [CrossRef]

28. Zhang, H.; Wang, X.; Li, Z.; Zhou, Y. Al stabilized TiC twinning platelets. J. Mater. Res. 2014, 29, 1113-1121. [CrossRef]

29. Emmerlich, J.; Music, D.; Eklund, P.; Wilhelmsson, O.; Jansson, U.; Schneider, J.M.; Högberg, H.; Hultman, L. Thermal stability of $\mathrm{Ti}_{3} \mathrm{SiC}_{2}$ thin films. Acta Mater. 2007, 55, 1479-1488. [CrossRef]

30. Momma, K.; Izumi, F. VESTA 3 for three-dimensional visualization of crystal, volumetric and morphology data. J. Appl. Crystallogr. 2011, 44, 1272-1276. [CrossRef] 